\title{
Why public organizations contribute to crosscutting policy programs: the role of structure, culture, and ministerial control
}

\author{
Astrid Molenveld ${ }^{1,2} \cdot$ Koen Verhoest ${ }^{2} \cdot$ Jan Wynen ${ }^{2,3}$
}

Published online: 5 September 2020

(c) The Author(s) 2020, corrected publication 2020

\begin{abstract}
The extent to which public organizations contribute to crosscutting policy programs is a question of organizational commitment, resource allocation, and monitoring. In this paper, we triangulate survey and interview data to study the explanatory power of organizational factors to understand the extent of organizational adaptation to crosscutting policy programs. In line with the hypotheses, the organizational task, culture, and the portfolio minister's level of control seem to explain the extent of adaptation. Policy development as a task has a positive effect on organizational adaptation. However, this effect disappears if we add cultural variables. The second model indicates that a customer-oriented culture has a negative effect on organizational adaptation, and an innovation-oriented culture has a positive one. The portfolio minister's level of control has a strong positive effect on organizational adaptation. Apparently, incentives are needed to hold organizations accountable and provide them clear direction regarding their contribution to crosscutting objectives.
\end{abstract}

Keywords Crosscutting policy · Organizational adaptation · Innovation-oriented culture Customer-oriented culture $\cdot$ Ministerial control $\cdot$ Accountability Although author sequence is alphabetical, the first two authors have the largest contribution, and they
contributed equally to this paper and can hence alternate the order of names.

Astrid Molenveld

molenveld@essb.eur.nl

Koen Verhoest

koen.verhoest@uantwerpen.be

Jan Wynen

jan.wynen@uantwerpen.be

1 Department of Public Administration and Sociology, Erasmus University Rotterdam, Burgemeester Oudlaan 50, 3062 PA Rotterdam, The Netherlands

2 Department of Political Science, Research Group on Politics and Public Governance, Sint Jacobstraat 2 - 4 S.M.286, 2000 Antwerp, Belgium

3 Faculty of Business and Economics, University of Antwerp, Sint - Jacobstraat 2 - S.M.272, 2000 Antwerp, Belgium 


\section{Introduction}

Governments nowadays face demands for integrated service delivery and are expected to cooperate across organizational borders to solve wicked problems, a quest which creates a considerable need for coordination (Klijn and Koppenjan 2016; Peters 2015; Termeer et al. 2013). The vastly expanding literature is rather negative about inter-organizational coordination. Scholars have provided extensive lists of failure factors, a central one being the lack of cooperation among public organizations (see e.g., 6 et al. 1999; Candel 2017; Tosun \& Lang 2017). Due to New Public Management reforms and agencification, crosscutting type of work has become more difficult (Head and Alford 2015, p. 720). Most public administration systems are post-NPM strongly compartmentalized, and sectoral and organizational logics predominate, the latter constraining inter-organizational collaboration (Peters 2018; Christensen and Lægreid 2007; Ling 2002).

A central challenge in contemporary public administration is how to foster the achievement of crosscutting policy programs in a system organized by sectoral logics (Carey et al. 2015; Karré et al. 2013). Individual public organizations face numerous obstacles when attempting to contribute to crosscutting policy programs, as results are often not immediately visible or are irrelevant to their own organizational goals, and organizations fear a loss of power, autonomy, or control over budgets (6 et al. 1999). Moreover, control signals, incentives, and accountability are usually organized vertically along organizational and sector lines (Bouckaert et al. 2010; Pollitt 2003). Hence, the incentives of individual CEOs and their organizations are strongly directed toward achieving their own organizational objectives (Peters 2018). Consequently, "minding their own shop" comes first (p. 66 et al. 1999, p. 66).

Moreover, the coordination of crosscutting policy programs is characterized by diffuse control and accountability arrangements without a clear allocation of responsibility and a lack of strong incentives (Tosun and Lang 2017; Candel 2017; Lægreid et al. 2014; Bouckaert et al. 2010). This situation creates "the problem of many eyes" (Bovens 2007, p. 455; Page 2013) due to the involvement of multiple accountability forums and the fact that control signals for such objectives cut across vertical control lines (Lægreid et al. 2014; Ross et al. 2011). Organizations hence face partially conflicting control signals, which make prioritizing these crosscutting objectives difficult, especially when organizational resources are scarce.

The literature acknowledges that coordination is time-consuming and costly; nevertheless, these (financial and non-financial) efforts and resources are key to success (Lægreid et al. 2014; Carey and Crammond 2015; Scott and Thomas 2017). However, crosscutting policy programs face a collective action problem in the form of free-rider behavior and the multiple-agents problem; no single organization feels responsible or wants to commit resources, hoping instead that other organizations will invest sufficient resources (Klijn and Koppenjan 2000; Scott and Thomas 2017).

The literature on coordination deals quite extensively with the design of coordination arrangements for crosscutting policy programs, both in instrumental and institutional terms, and how public organizations can be encouraged to contribute to its design (see e.g., Cejudo and Michel 2017; Carayannopoulos 2017; Trein 2017; Nordbeck and Steurer 2016; Christensen et al. 2016; Carey et al. 2015; Molenveld et al. 2020). However, the literature is much less explicit about the implementing organizations and how different organizationspecific factors influence the extent of their contribution to such programs (cf. Christensen et al. 2012). A theory on coordination of crosscutting policy programs should not only 
encompass the macro-level coordination elements (design of the coordination arrangement) but also meso-level insights on which organizational features come into play during the implementation. Such insights might help to substantiate the emerging call in the literature for adaptive and reflexive coordination approaches (see e.g., Carey and Harris 2016; Meuleman 2008; O'Flynn et al. 2011; Voets et al. 2015) that take into account the diversity of implementing organizations. In this paper, we seek to explain the extent to which individual organizations contribute to crosscutting policy programs, and we operationalize this as the extent to which organizations adapt themselves to these objectives-hence the term organizational adaptation. The central research question is hence: Which organizational factors explain public organizations' contribution (measured through organizational adaptation in terms of their commitment, allocation of responsibilities and resources, monitoring, and reporting) to crosscutting policy programs?

We studied this puzzle in the context of a crosscutting policy program in the Flemish Government called "Flanders in Action" (FiA), which was designed by the prime minister (called Minister-President) and his administration. All public sector organizations are involved in the program to a certain extent, thus allowing us to study the influence of different organizational variables, as well as the impact of the portfolio minister's level of vertical control, while keeping other elements constant. We note that the notion of "portfolio minister" in this paper refers to the sectoral minister under which the organization resides and to which the organization is accountable. Using survey data, we ran regression analyses and also used quotes from interviews to further interpret the results. In the following sections, we first elaborate on the conceptual and theoretical perspective used throughout this article. Then, we introduce the hypotheses, which were developed by drawing upon the literature on coordination, policy integration, and public organizations. Thereafter, we present the case and the methods used, followed by the results of the analyses. As our theoretical framework is already rather encompassing in terms of variables and due to the limited size of our dataset $(N=44)$, we do not include additional control variables in the analyses shown in the paper. However, we performed several additional analyses with other variables (i.e., organizational size; whether the organizations' portfolio minister is also the minister responsible for the most important crosscutting objective the organization contributes too; and the extent of substantive links of the crosscutting objective with the many ongoing activities of the organization) which are described in the paper at length. In the last part of the article, we conclude with a discussion and a conclusion.

\section{Theoretical and conceptual framework}

Crosscutting policy programs can be seen as an external requirement which organizations need to integrate, in order to be strategically effective (according to Thompson 1967; see also Karré et al. 2012, p. 99). If core practices stay the same while new issues need to be integrated, low performance is likely (Christensen et al. 2007a, b; Lombardo and Mulligan 2003, pp. 6-7).

As the literature shows, individual organizations often perceive crosscutting policy programs as new claims for scarce organizational resources and efforts that compete with the organizational objectives that they have to meet (6 et al. 1999, pp. 27-28; Pollitt 2003; Christensen et al. 2007; Ross et al. 2011; Peters 2015; Candel 2017). Integrating crosscutting policy programs into organizational activities implies, in most cases, a realignment of the existing activities, a change of procedures, new or reoriented activities, as well as 
increased interaction with other actors (e.g., ministers, departments, and agencies). Such an integration demands resources and efforts - to not only plan, monitor, and evaluate these objectives but to deal with the implied changes to primary production processes in the organization (Carey and Crammond 2015). Bouckaert et al. (2010; see also Alexander 1995; Peters 2015; Rogers and Whetten 1982) argued that a low level of organizational interest in realigning efforts toward crosscutting policy programs constitutes one of the most prevalent failure factors for coordination.

Furthermore, crosscutting problems, as well as their solutions, are complex by definition, and such programs have a higher risk of failure than those with problems and solutions confined to a single sector or organization (6 et al. 1999; Pollitt 2003; Peters 2015; Candel 2017). Senior managers of public sector organizations are less willing to invest resources and time in activities with a relatively high chance of failure (6 et al. 2002); they prefer to invest in simpler, single-sector policies that align with the primary purpose of their organizations. Some scholars have identified organizations' fear that coordination will negatively influence the effectiveness of their core activities as one of the main factors for failure to coordinate with other organizations (Rogers and Whetten 1982; Alexander 1995). Moreover, as crosscutting policy programs have a predominantly long-term orientation (Lægreid et al. 2013), organizations assign less value to them since they do not expect to receive a benefit in the immediate future (Kollock et al. 1992).

Hence, for public organizations, contributing to crosscutting policy programs clearly comes with costs and risks, and thus, this consideration affects their decision as to whether or not to adapt their organizations to these objectives. Thus, in this paper, we measure the organizational contribution not in terms of outcome, but rather in terms of the extent to which they adapt their organization: in terms of their commitment, allocation of responsibilities and resources, monitoring, and reporting. We opted to focus on organizational adaptation, on the one hand because outcomes are hard to measure and often intangible, and on the other hand, because effects of a program only manifest themselves after several years. Moreover, we study the self-reported adaptation of organizations to crosscutting objectives and not the actual implementation. Although this is only a proxy for the de facto implementation and outcomes of the crosscutting issue, it provides a good indication of the first step toward the actual achievement of crosscutting objectives.

Hence, organizational adaptation refers first to the extent to which organizations adapt their structures and processes in order to implement crosscutting objectives. When an organization allocates resources, assigns specific responsibilities to these objectives, and integrates them into internal monitoring and reporting systems, one could argue that these crosscutting objectives become institutionalized (Jordan and Schout 2006; Salamon 2002). Adapting to crosscutting policy programs only in terms of structures and processes is not enough for organizations to really internalize these programs (Christensen and Lægreid 2007). Focusing solely on structure might merely conceal an organizational "myth" and structural decoupling (Meyer and Rowan 1977; Jun and Weare 2011; Carey et al. 2015). Next to adaptation in terms of structures and processes, Ling (2002) shows that an increase in commitment and prioritizing crosscutting actions are crucial conditions for joined-up government (Christensen and Lægreid 2007).

We hypothesize that the extent of organizational adaptation is influenced by different structural factors, such as the formal legal distance toward government, the de facto management autonomy of the organization, and the nature of its task, as well as by certain dimensions of the organizational culture. Moreover, the vertical control that the organization's portfolio minister exerts can also play a role. In the next paragraph, we describe the most prominent factors influencing organizational adaptation. 


\section{Structural organizational factors affecting organizational adaptation to crosscutting objectives}

The first factor that determines the extent to which organizations internally adapt to crosscutting objectives is their institutional location within the government apparatus or, stated differently, their formal legal distance from central government. Some scholars have identified the disaggregation of organizational units into autonomous agencies as a major element within NPM reforms that makes coordinated action much more difficult (Bouckaert et al. 2010; Trein et al. 2019), particularly in agencies with their own legal identity vested in public or private law (Peters 2015; van Thiel 2012; Verhoest et al. 2012). (Semi-) autonomous agencies, which are at a greater distance from government, are focused and narrow in their objectives; that is, they are single-purpose agencies. These agencies' narrow objectives, which are laid out in their enacting statutes, define the legal basis for their existence, which makes it harder for them to take on extra objectives or new tasks that do not align directly with their statutory objectives. Moreover, the legal status of such agencies gives them formal autonomy, shielding them from ministerial interference, which makes control more difficult (Verhoest et al. 2004; Christensen 2001). This is the case for the control of vertical objectives but even more so for control regarding horizontal objectives. Also, most agencies have their own governing boards with the role of strategically steering and supervising the agency with respect to its statutory goals. Interest groups are represented on the board as well. The interest groups and client organizations in the governing board of such agencies have a strong interest in ensuring that the agency devotes the maximum amount of resources and effort to achieve its statutorily defined goals, as this benefits the actors that they represent (for a similar argument in structural choice theory, see, e.g., Moe 1990). Finally, agencies are more visible and identifiable in society, compared to departments for instance, so these organizations put forth their best efforts in performing well in terms of their statutorily defined objectives (Bertelli 2016; Schillemans and Jacobs 2014).

Organizations without their own legal identity that are positioned close to central government (like departments or departmental agencies) are formally under the full authority of their portfolio ministers. Hence, their political principals have a certain flexibility in terms of the objectives they want these organizations to pursue. Even within the broadly defined objectives of such organizations, ministers can quite easily impose additional tasks upon them (van Thiel 2012). The relationship with the political principal in this arrangement is hierarchical, and the power between the players is unequal. It lies with the principal (Schillemans 2013). As departments and other organizations closest to government tend to be more multi-functional and composed of different units that focus on distinct objectives, they have more leeway to shift resources from one objective to another and from one unit to another if the executive politicians' desire and mandate such actions. Moreover, a diversity of functions and purposes increases contacts with other organizations and increases the openness to coordination (Rogers and Whetten 1982); that is, specialization hinders coordination (Peters 2018). These considerations led to the formulation of the following hypothesis.

Hypothesis 1 Public organizations close to the central government (low formal legal distance) will exhibit a higher level of organizational adaptation to crosscutting objectives compared to organizations with a greater formal legal distance from central government. 
As noted by many agency researchers, formal autonomy stemming from the legal status of a public sector organization does not always imply similar levels of de facto autonomy (Maggetti 2012; Verhoest et al. 2004; Yesilkagit and van Thiel 2008). A low level of de facto management autonomy limits organizations' ability to choose the inputs they actually need and to optimally allocate these inputs across different activities or objectives (Verhoest and Wynen 2018). However, coordination and collaboration with other organizations in order to implement crosscutting objectives permit organizations to move quickly and seize unexpected opportunities; hence, this approach requires the organizations involved to have the capacity to shift resources across units of the organization and across activities, or even to share resources between organizations (Emerson et al. 2012; Scott and Thomas 2017). Therefore, agencies with more de facto management autonomy also have more flexibility to freely invest resources in activities contributing to crosscutting objectives. Agencies with extended de facto management autonomy with respect to human resources (HR) can more easily attract and motivate staff with the competencies needed to fulfill crosscutting objectives and to function in intensive relationships with collaborating organizations. Also, organizations with strategic personnel management autonomy can even award collaborative behavior and the achievement of crosscutting objectives through adjusted compensation, promotions, and evaluation criteria for staff. Therefore, the second hypothesis stands somewhat in contrast to the previous hypothesis.

Hypothesis 2 Public organizations with relatively high levels of de facto personnel management autonomy can be expected to exhibit a higher level of organizational adaptation to crosscutting objectives compared to organizations with relatively low levels of de facto personnel management autonomy.

Moreover, the nature of the primary task that the organization performs matters. The task portfolio of an organization defines the technical environment of an organization, which functionally and institutionally determines the behavior and role definitions of individuals in organizations and of the organizations themselves (Thompson 1967; Christensen et al. 2007a, b; Maggetti and Verhoest 2014). In the most basic terms, public sector organizations are involved in policy development or policy implementation (through service delivery, regulation, subsidies, and taxation). One may argue that coordination at the level of "text" - which is basically what coordination of policy development is about-is easier for the organizations involved to integrate as an activity compared to the coordination of "actions" (i.e., coordination of policy implementation and service delivery) (Bouckaert et al. 2010). For organizations involved in policy development, coordination mainly means interacting with other actors in order to include their preferences in policy documents, with little real impact on their own processes. Therefore, such organizations' contributions to crosscutting objectives are usually geared toward integrating these objectives into their own policy plans. However, for organizations with policy implementation objectives, the coordination of their actions with other organizations requires changes to internal procedures and processes. Moreover, coordination regarding crosscutting objectives (e.g., to make service delivery more seamless) has a real impact on the different organizations' ways of working, entails substantial costs in terms of resources and effort, and affects organizational priorities. Based on these considerations, the third hypothesis was formulated. 
Hypothesis 3 Public organizations that have policy development as a primary task will exhibit a higher level of organizational adaptation to crosscutting objectives compared to organizations with policy implementation as a primary task.

\section{Cultural organizational factors affecting organizational adaptation to crosscutting objectives}

Organizational culture also plays a role in determining whether or not an organization is motivated to contribute to crosscutting objectives and can easily adapt to such objectives (Carey and Crammond 2015; Christensen et al. 2016; Carayannopoulos 2017; Tosun and Lang 2017). The culture of an organization has an influence on what behavior the staff and managers of the organization perceive as being appropriate (see the cultural-institutional perspective in organization theory in the work of Christensen et al. 2007). Based on international cases of coordination in the public sector, Lægreid et al. (2014, p. 271; see also Laegreid and Rykkja 2015) asserted that "organizational culture is crucial-whether it supports cross-border coordination or not." We expect two dimensions of organizational culture to be particularly relevant in this regard: an innovation-oriented culture and a customer-oriented culture.

First, building upon the literature on coordination and public sector innovation, we argue that public organizations that seek innovation in their services and processes are more open to collaboration and coordination with other organizations (Sorensen and Torfing 2011; De Vries et al. 2016). According to Carey and Crammond (2015, p. 1024; see also O'Flynn et al. 2011), successful whole-of-government initiatives are characterized by organizations with cultures "conducive to problem-solving, where staff are free to find "work-arounds" to problems." Rogers and Whetten (1982) stated that having cultural norms geared toward innovation increases the motivation for organizations to coordinate; according to Pollitt (2003), innovation is one of the motivating factors for organizations to invest in joined-up working. Moreover, to handle crosscutting objectives well and to integrate them efficiently in ongoing organizational processes, organizations need a culture that values risk taking, creativity, and experimentation, as well as employees who can "think outside the box" beyond the boundaries of the organizations involved and the task at hand (van Bueren et al. 2003). These considerations led to the formulation of the following hypothesis.

Hypothesis 4 Public organizations with a culture oriented more strongly toward innovation will show a higher level of organizational adaptation to crosscutting objectives compared to organizations with a less innovation-oriented culture.

Second, public organizations with an organizational culture that highly values responsiveness to customers' demands and service quality tend to be particularly sensitive and alert regarding ill-coordinated policies and services that (might) create problems and dissatisfaction among users. An external focus on what users and customers want stimulates organizations to take a holistic view and a more integrative attitude toward policies and services, in contrast to organizations that mainly have an internal focus (Ling 2002; Pollitt 2003; Bouckaert et al. 2010; Peters 2015). As Bogdanor (2005; see also Tosun and Lang 2017) illustrated, a crucial driver for joined-up government initiatives is the demand from users for better and seamless public services. In this perspective, a customer-oriented organizational culture may be assumed to foster a collaborative attitude within public organizations, making them willing 
to coordinate with other organizations and to contribute to crosscutting objectives. Drawing on the information presented above, the following hypothesis was formulated.

Hypothesis 5 Public organizations with an organizational culture oriented more strongly toward customers may be expected to exhibit a higher level of organizational adaptation to crosscutting objectives compared to organizations with a less customer-oriented culture.

\section{Vertical control of the portfolio minister as a factor affecting organizational adaptation to crosscutting objectives}

The structural and cultural factors mentioned above may be expected to impact the extent to which organizations put effort into achieving crosscutting objectives by adapting their internal structures, processes, and commitment. However, this also depends on control signals and the accountability arrangements the organizations are confronted with (Tosun and Lang 2017). The literature on coordination indeed indicates that accountability and incentives for the achievement of crosscutting objectives are a major driver for coordination (Peters 2015; Bouckaert et al. 2010; Rogers and Whetten 1982). Peters (2018) asserted that "performance management... has had a particularly negative effect on coordination. By setting targets of an organization, it will tend to ignore collective goals" (see also Pollitt 2003). Taking into account the network-like features of horizontal coordination arrangements (i.e., lack of hierarchical power and strong incentives), the achievement of crosscutting objectives necessitates the integration of crosscutting objectives within the traditional sector-based, vertical lines of control and accountability, and the incentives used in this vertical relationship should be linked to accomplish these goals (Lægreid et al. 2014; Carey and Crammond 2015). In this view, crosscutting objectives have a higher priority within individual public sector organizations when portfolio ministers steer them and hold senior management accountable for achieving the objectives (Schillemans 2013). In such cases, crosscutting objectives receive much the same treatment as the sectoral and organizational objectives through the use of the same vertical control and control instruments (i.e., "verticalization of horizontal policy"). The ideas presented above led to the formulation of the following hypothesis.

Hypothesis 6 Public organizations that are steered and held accountable to a high extent by their portfolio ministers regarding the achievement of these crosscutting objectives will exhibit higher levels of organizational adaptation to crosscutting objectives compared to organizations where this is only the case to a relatively low extent.

\section{The case}

We tested the hypotheses by studying the extent of organizational adaptation of Flemish public organizations to crosscutting objectives that are part of the government-wide FiA policy program.

\section{The Flemish administration}

Flanders is one of the autonomous regions of the Belgian federal system, with its own parliament, cabinet, and public administration consisting of departments and agencies. The 
region is a full-fledged state for the competencies under its remit due to the "dual federalism" in the Belgian state (Swenden et al. 2006). The Flemish administration has some features-similar to several other European countries like the Netherlands, Denmark, or Norway - that limit organizations' crosscutting coordination capacity (Bouckaert et al. 2010; Lægreid et al. 2014). First, the minister-president is "primus inter pares" and has no formal authority to instruct other ministers. More generally, no minister supersedes another (Brans and Hondeghem 2005). Moreover, the three central departments responsible for finances, budget, civil service regulations, and horizontal policies do not hold authoritative power and cannot instruct line departments and agencies. Furthermore, throughout the history of the Flemish administration, but more radically through a major administrative reform in 2006 (called "Beter Bestuurlijk Beleid" [BBB] in Dutch, loosely translated as: better governance policy), more (semi-) autonomous agencies have been created with substantial degrees of management autonomy. Departments and agencies are clustered in 13 policy domains, which are called "ministries," and each ministry would contain one department and multiple agencies. In most policy domains, relations between departments and agencies are characterized by tensions with respect to the departments' authority to control agencies and the division of tasks (Rommel and Christiaens 2009; Verhoest et al. 2012). Traditionally, control relations, accountability, and budgetary arrangements are organized vertically along the lines of ministries and individual organizations. The coalition agreement is translated by each portfolio minister into sectoral policy statements, which are further operationalized into management contracts that departments and agencies conclude with their respective portfolio minister. Accountability is predominantly ensured through the monitoring of these contracts and the evaluation of the CEOs by the portfolio minister, who is in turn accountable to sector-specific parliamentary committees. Since the mid-2000s, more effort has been put into creating coordination arrangements to deal with complex policy issues and overarching administrative issues. However, these coordination arrangements are still generally considered rather weak. Several reports have indicated that strengthening crosscutting coordination and fighting compartmentalization are two major challenges for the Flemish government (OECD 2007; Serv 2009; Verhoest et al. 2013). The government-wide FiA policy program was a clear attempt to deal with complex policy problems through concerted actions across policy domains and ministerial portfolios.

\section{Flanders in Action (FiA)}

Aspiring to position Flanders as one of the five most developed regions in Europe by 2020, the Flemish minister-president initiated FiA, a long-term, government-wide policy program for Flanders, in 2006. The development of the policy program was a politically initiated co-creation process in the period 2007-2009, with civil society organizations and interest groups being involved in drawing up seven crosscutting themes as overarching objectives for future governments. These themes are: (1) The open entrepreneur; (2) Flanders learning society; (3) Innovation Centre Flanders; (4) Green and dynamic urban region; (5) Europe's smart hub; (6) Caring society; and (7) Decisive governance. These themes are explained in more detail in "Appendix 1."

After the co-creation process, FiA and its themes were firmly anchored in the 2009-2014 coalition agreement of the next cabinet. To implement the program, the Flemish government and its administration further developed the themes into crosscutting key projects and action plans (for an in-depth description, see Molenveld and Verhoest 2014). In order to coordinate and monitor the program's progress and the seven crosscutting 
themes, a common governance structure with horizontal coordination arrangements was installed. First, for each of the seven themes, a minister with the portfolio most closely affiliated with the theme was assigned a coordinating role. Moreover, for each theme, a top civil servant, based on his or her thematic expertise, was appointed by the Flemish government as a "champion" (Agranoff 2006). The key projects were led by administrative project managers responsible for coordinating the actions, although they were not provided with extra resources. On a regular basis, "the champion" of each theme consulted the coordinating minister, contributing ministers, and project managers about the implementation of FiA in theme groups. The coordinating ministers, the "champions," and the project managers had no hierarchical power over the other contributing organizations. The only exception is that the coordinating ministers could instruct the organizations within their own portfolios to cooperate, but they did not have any such power in organizations in other ministries (Molenveld and Verhoest 2014).

Across the seven themes, progress was monitored by the "Committee of Top Civil Servants," which represents the 13 ministries. An interdepartmental working group assisted the committee, together with a staff unit in the Department of Governmental Affairs. The working group and the staff unit regularly requested information from the theme groups, as well as all the departments and agencies, regarding their contributions to crosscutting objectives, projects, and action plans, and they then inserted this information into a central monitoring instrument. The contributing departments and agencies received no extra budgets or other resources for the implementation of FiA, so FiA had to be implemented within the budgets already allocated to these organizations.

To sum up, we can say that FiA has a rather loosely coupled coordination structure with network-based instruments, a relation based on trust, and an implementation structure with a great deal of autonomy for the organizations (Molenveld and Verhoest 2014). These features of FiA are very similar to horizontal programs or whole-of-government approaches in most EU countries, which share these network-like features, lack pooled, or joint resources, and have no central control capacity to force individual organizations to contribute to crosscutting objectives (Carey and Crammond 2015; Lægreid et al. 2014; Bouckaert et al. 2010). The Flemish politico-administrative systems have some particular features like being embedded in a federal country, having a small size which enables personal contact, and a considerable politicization of the administrative system with ministers having a high number of politically appointed ministerial advisors (compared to the French "cabinets de ministre"). This combination of specific features makes it to some extent distinct from other European countries. On the other hand, the features which limit the central coordination capacity, like the primus inter pares role of the prime minister, the high degree of departmentalization and agencification, and the weak power of the central departments (like the department of civil service) has resemblance with several other countries like the Netherlands, Norway, and Denmark (Verhoest et al. 2012). Like in several other OECD countries, the government apparatus in Flanders is "loosely coupled" (Chisholm 1992; Bouckaert et al. 2010), with a high degree of compartmentalization and agencification, and rather weak horizontal coordination mechanisms. In order to get this crosscutting policy program implemented, many networks and forums were put in place to govern the objectives. Also the reliance on predominantly network-like coordination mechanisms for crosscutting objectives is recognizable in several European countries (Lægreid et al. 2014; Carey and Crammond 2015; Candel 2017). Although we cannot claim that the Flemish FiA case is a "typical case" (Yin 2014), there are aspects which are comparable to other countries and which speak to the literature on coordination of crosscutting issues (see e.g., Candel 2017). 


\section{Methods}

We are interested in the extent to which organizational factors can explain organizational adaptation to crosscutting objectives by government agencies and departments. To this end, we studied one case, the FiA program, with many embedded cases, namely the 60 departments, departmental agencies, and public law agencies. The characteristics of the program (in terms of resources and the horizontal coordination arrangements) are the same for each organization; what varies is the level of vertical control the portfolio minister has over crosscutting objectives as well as the organizational structures and cultures. We used two data sources: surveys and interviews. We collected the survey data with the second edition of the COBRA survey. COBRA refers to the "Comparative Public Organization Data Base for Research and Analysis" network (http://soc.kuleuven.be/io/cost/survey/). The network developed a common questionnaire in order to survey CEOs of public sector organizations.

Through the use of a personalized link, CEOs from departments and agencies were asked to complete the online survey in the period from January to April 2013, seven years after FiA was first launched. At that time, the implementation of the FiA program was at full strength, which was also confirmed by interviews (see below). The monitoring report of December 2012 (before the survey was launched) that of the 335 key projects within this project, $77.5 \%$ was well on schedule in their implementation, $10 \%$ was already completed, while $11.5 \%$ was delayed (see also Molenveld and Verhoest 2014). As to the survey, an overall response rate of $75 \%$ was achieved, with $66 \%$ of the responses stemming from departments and $77 \%$ from the agencies (46 organizations in total). A Chi-squared goodness-of-fit test was performed to check whether the distribution of the sample by formal legal distance matches the distribution within the full population of 60 organizations. The results reveal that the breakdown by formal legal distance of the organizations is not significantly different compared to the population (Flemish government) (Chi squared with three degrees of freedom $=1.92, p=0.5901$ ).

The CEO of each organization was asked to answer on behalf of the entire organization. The logic is that the perception of CEOs determines the way they decide to manage their organizations (Verhoest et al. 2007; Lægreid et al. 2011).

\section{Dependent variable}

Organizational adaptation is the dependent variable in this study. We explained the concept in detail in the theoretical part of this paper. The variable is based on three dimensions, referring to adaptation in terms of (1) commitment, (2) allocation of responsibilities and resources, and (3) monitoring and reporting. First, from the seven themes of FiA, the respondents were asked to select the objective in which they were most intensively involved (compared to the other objectives). In the next question, they were asked to what extent they agreed with the statements, as presented in Table 1. For each of the items, a 5-point scale was used (strongly agree-somewhat agree-neither agree nor disagreesomewhat disagree-strongly disagree). Table 1 shows the average, standard deviation, minimum, and maximum per item. The average per item varies between 3 and 4, with the average for the item with respect to the allocation of resources to be the lowest. Factor analysis shows that the six items clearly load on the same factor, meaning that the items coevolve in the survey responses and that an index of these items can be used to measure the concept of "organizational adaptation." Hence, the scores of the items were aggregated, 


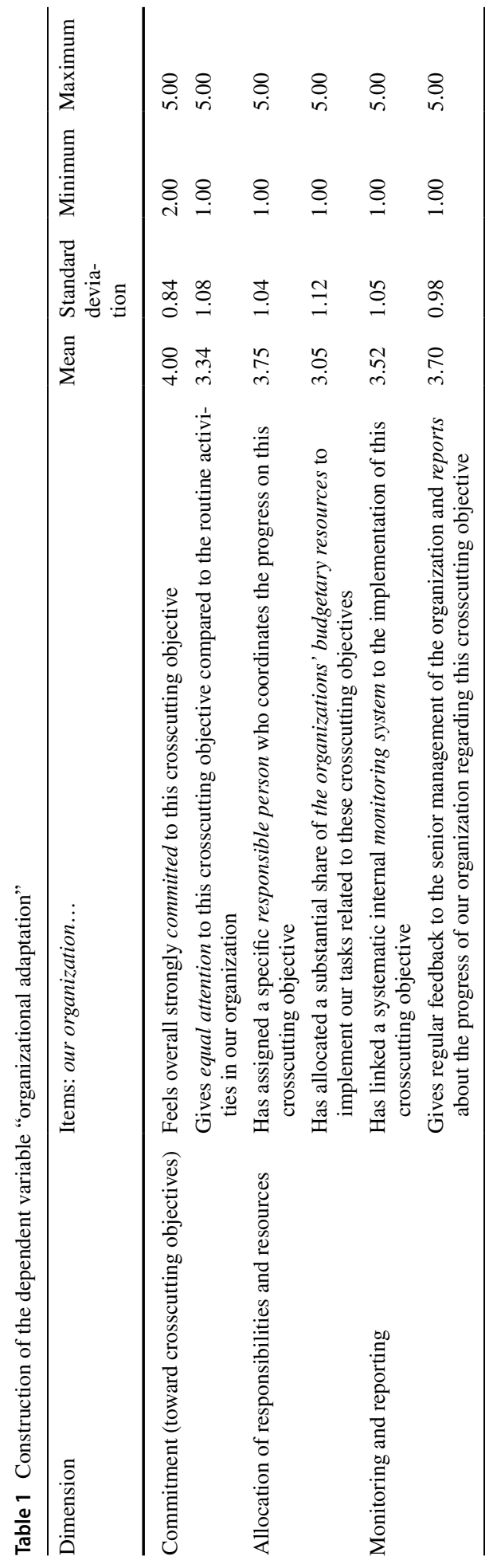


Table 2 Extent of "organizational adaptation" per crosscutting objective within FiA

\begin{tabular}{llll}
\hline $\begin{array}{l}\text { Themes of Flanders in Action (FIA) as crosscutting } \\
\text { policy program }\end{array}$ & \multicolumn{2}{l}{\begin{tabular}{l} 
Index of organizational adaptation \\
\cline { 2 - 3 }
\end{tabular}} & $\begin{array}{l}\text { Number of } \\
\text { organizations } \\
\text { Frean }\end{array}$ \\
\hline 1. The open entrepreneur & 0.11 & Std. dev & 3.00 \\
2. Lifelong learning & 0.46 & 0.13 & 4.00 \\
3. Innovation center Flanders & 0.46 & 0.31 & 2.00 \\
4. Green and dynamic region of cities & 0.24 & 0.17 & 9.00 \\
5. Smart distribution center of Europe & 0.56 & 0.39 & 3.00 \\
6. Warm society & 0.26 & 0.33 & 8.00 \\
7. Decisive government (7 sub-objectives) & 0.5 & 0.22 & 15.00 \\
\hline
\end{tabular}

and an index of "organizational adaptation" was created by taking the average. The index of organizational adaptation has a Cronbach's alpha of 0.8648. (Cronbach's alpha of this index is high: 0.86). Since the distribution was non-normal, the log of this variable was used in the subsequent analyses.

Table 2 shows the seven crosscutting objectives and gives further information about the average and standard deviation of the "organizational adaptation" index per objective, as well as the number of organizations which mention the involved FIA objective as the one they contribute to the most (in comparison with the other objectives). "Appendix 2" shows a table including how the 44 organizations are distributed across the 13 ministries and 7 themes (as well as indicating which ministry is the lead for each theme). We see that the number of organizations as well as the extent of organizational adaptation differs across the objectives. These differences might be due to the different structural and cultural features of the organizations of the contributing organizations, as well as the vertical control of their portfolio minister regarding the involved FIA objective (see for the analyses below). We also perform some additional robustness checks with variables which relate to the specific FIA objective (see below). However, it is likely that a part of the variation with respect to organizational adaptation across the objectives is due to other factors of a more idiosyncratic nature of the involved crosscutting objectives. However, due to the low number of organizations working on each FIA objective, we cannot integrate further variables related to the specific nature of the crosscutting objective into the analyses.

\section{Independent variables}

We took six independent variables into account as factors regarding organizational structure and culture, as well as vertical control (of the portfolio minister).

Formal legal distance: Legal distance from government was coded as a dummy variable, with a value of 1 for agencies with their own legal identity (i.e., separate from the state, vested in public or private law); otherwise, the value was set to 0 . This variable has been coded by the researchers based on statutory information about the organizations' legal status.

De facto personnel management autonomy: For this variable, we used strategic managerial autonomy regarding human resources (HR), referring to the extent to which an organization has the ability to decide upon regulations, procedures, and criteria concerning the salary level, appointment, promotion, evaluation, dismissal, and the total number 
of staff itself without interference from above (ministers or central departments). For each of the three items, organizations could respond to this by selecting "for all of their staff," "for most of their staff," "for some of their staff," or "not at all." An index was created by aggregating these items (Cronbach's alpha of 0.7). Based on that index, a variable was constructed with a value equal to 0 for organizations that scored lower than the average; otherwise, the variable was set to 1 .

Having policy development as primary organizational task: For this task, we distinguished between policy development and implementation. The dummy equals 1 if the organization's primary task is policy development. All tasks related to policy implementation were set to 0 . In Flanders, often, departments combine policy development as a primary task with minor aspects of policy implementation. In that case, the departments' primary task was coded as policy development. Most agencies, although not all, have policy implementation as their primary tasks. This variable has been coded by the researchers based on statutory information about the organizations' tasks.

Innovation-oriented and customer-oriented culture: Organizational culture is multidimensional in kind, and several analytical frameworks and measurements have been developed to study this concept. A measurement instrument for organizational culture as developed and tested by Tepeci (2001) was used in the original COBRA survey (see also Lægreid et al. 2011), as well as in the survey used in this study. The survey instrument developed by Tepeci (2001) and used in the COBRA survey contains an encompassing 36-item survey battery to measure 9 dimensions of organizational culture, each by 4 items. The respondents were asked to score these 36 items according to the extent to which this feature was characteristic of the organization on a 7-point scale ranging from "very characteristic" to "very uncharacteristic." The internal consistency of each of the different dimensions was confirmed by COBRA research. ${ }^{1}$ Following Tepeci's (2001) clustering of culture items, "innovation-oriented culture" was measured in terms of the extent to which the following four aspects are valued within an organization (see also Lægreid et al. 2011): (1) risk taking, (2) experimentation, (3) creativity, and (4) innovation (Tepeci 2001; see also Lægreid et al. 2011; Wynen et al. 2013; Wynen and Verhoest 2015). The set of items as suggested by Tepeci to measure the dimension of customer-oriented culture was used to construct the "customer-oriented culture" variable: (1) emphasizing quality of service delivery, (2) giving customers what they expect, (3) valuing customers, and (4) maintaining relationships with customers. In line with Tepeci's study and earlier COBRA research, the Cronbach's alpha values for both variables are high ( 0.75 for innovation-oriented culture and 0.79 for customer-oriented culture, respectively).

Vertical control of the portfolio minister regarding crosscutting objectives: This independent variable was constructed as an index on the basis of four items referring to the vertical control (of the portfolio minister) in terms of attention to the crosscutting objective by the portfolio minister as perceived by the CEO of the organization. The portfolio minister is responsible for the organizations under his or her remit items which refer to the control by other actors like the ministerial management committee or horizontal departments have

\footnotetext{
1 See https://soc.kuleuven.be/io/cost/survey/surv_core.pdf. The different dimensions of organizational culture measured through the survey items are: goal oriented; customer oriented; innovation oriented; people oriented team oriented; fair compensation; oriented toward the development of employees; detail oriented; oriented toward honesty and ethical behavior. In this article, we use focus on two of these dimensions, being innovation-oriented culture and customer-oriented culture, using for each the four items as Tepeci developed them and as confirmed by COBRA research. Also in this study, the internal consistency is confirmed by the high Cronbach's alpha values for both kinds of culture.
} 
been excluded. The respondents were asked how strongly they agreed or disagreed with the following statements:

With respect to the FiA objective that you selected as the one your organization is most intensively involved in, is there attention for your organization's contribution to this crosscutting objective by the portfolio minister:

1. during the bilateral meeting between your organization and the portfolio minister about the design of the performance contract and business plan of the organization (a multi-annual contract that stresses obligations);

2. during the yearly evaluation of the performance agreement and business plan;

3. during the yearly evaluation of the senior management of the organization.

Also an item from the next question was used whether the organization experiences pressure to translate this crosscutting objective into internal objectives of the organization in your management and business plans by the portfolio minister.

For each of the items, a 5-point scale was used (strongly agree-somewhat agree-neither agree nor disagree — somewhat disagree—strongly disagree). The scores were aggregated, and an index of "organizational adaptation" was created by taking the average. Cronbach's alpha of this index is high (0.84). In "Appendix 3," we present the means and frequencies for each of the dependent and independent variables (including the components of the indices when appropriate), stratified by ministry and the departments and agencies.

Because all the data for the dependent variable and some of the independent variables (de facto personnel management autonomy, innovation-oriented culture, customer-oriented culture, and vertical control by portfolio minister) were self-reported and collected through the same questionnaire during the same period of time with a cross-sectional research design, common method variance (variance attributed to the measurement method rather than the constructs of interest) may have caused systematic measurement error and further biased the estimates of the true relationships among the theoretical constructs. In our study, researchers examined official policy documents to collect information on the formal legal status of the organization and the data used in the robustness checks (organizational size, organizations under the coordinating minister, and organizations led by the administrative coordinator). For variables that could not be verified using external sources, in addition to the use of interview data for the validation of the survey findings, extra steps in the survey design were taken to reduce the likelihood of common method bias.

First, a separation between the measures of the independent and dependent variables has been suggested as a way to reduce common method bias (CMB) in a survey (Podsakoff et al. 2012; Jakobsen and Jensen 2015, p. 17). Therefore, the respective set of questions for the different variables, which we had to measure through the survey, were placed in different locations of the survey and displayed as separate web pages, not in consecutive order. Second, in order to avoid issues of common method bias due to item characteristics, we tried to avoid and rephrase abstract items (Podsakoff et al. 2012; Meier \& O'Toole Jr 2013; Jakobsen and Jensen 2015). The independent variables "de facto personnel management autonomy" and "vertical control by the portfolio minister," as well as the dependent variable, refer to focused items and concrete practices that measure current states (see Jakobsen and Jensen 2015, p. 17). We asked respondents about their perceptions of their HR management autonomy, such as whether or not their organizations had the authority to decide on regulations, procedures, and criteria concerning the promotion of staff without interference from above (from ministers or central departments). Before launching the survey, it was piloted among potential respondents to check the comprehensibility of the 
survey items. Also, different answer categories were used to measure different independent variables like de facto personnel management autonomy and innovation-oriented culture, as well as to measure the dependent variable (5-point Likert scale), in order to avoid common scale properties (Jakobsen and Jensen 2015, p. 17). The use of concrete items for most of the variables diminished the capacity for personal interpretation and in turn reduced the likelihood that responses would be subject to social desirability effects and other underlying causes of common method bias. Finally, and most importantly, we analyzed evidence from interviews in order to check whether similar findings arose from this additional data source. These interviews were part of a larger project about the implementation of the FiA program and its subthemes. In total, 54 interviews were conducted with both coordinators and implementers of this crosscutting program. In the first round, open interviews with 25 coordinators were conducted, followed by 29 fully structured interviews. Respondents were selected of different organizations, in terms of type (departments and agencies), size, thematic focus, and ministry, this selection ensures that different options and standpoints were heard and taken into account. The first round of interviews concerned the tensions that coordinators experience during the implementation phase (based on the obstacles of 6 et al. 1999, p. 66). The respondents' perceptions of horizontal program coordination (Molenveld et al. 2020) and the subsequent organizational adaptation were the focus of the second round. The quotes presented in this article were specifically selected to explain the mechanisms shown in the statistical analyses. Quotes were not analyzed to check their representativeness for the whole population. However, we feel that the different focus of organizations with either an innovation- or customer-oriented culture is acknowledged by almost every respondent.

\section{Analysis and discussion of results}

Table 3 displays summary statistics for the main variables. Some variables appeared to be strongly correlated, so we tested for multicollinearity using the variance inflation factor (VIF). The mean VIF equals 1.67, leading to the conclusion that no collinearity exists between the variables; in other words, the shared variance of the variables is rather low, and their discriminant validity is potentially high.

\section{Econometric model and robustness checks}

In order to estimate our dependent variable, we made use of ordinary least squares (OLS). In order to check for possible misspecifications, we conducted a joint test of misspecification in several directions. More precisely, we applied the information matrix (IM) test, a test for the correct specification of a fully parametric model based on whether the IM equality holds. In short, this kind of approach allows researchers to test whether the null hypotheses of homoscedasticity, symmetry, and a kurtosis coefficient of 3 (e.g., Hall 1987) are satisfied. For all our estimations, the three assumptions of homoscedasticity, symmetry, and normal kurtosis cannot be rejected $\left(\chi^{2}(9)=8.02 ; \chi^{2}(22)=14.24 ; \chi^{2}(30)=29.78\right)$. The results are presented in three columns, to clarify how the robustness was tested (see Table 4 in the next section).

Several additional analyses were performed as robustness checks. In these models, additional variables were included in order to exclude alternative explanations. The results of the analyses are not included here but are available upon request. A first additional variable 


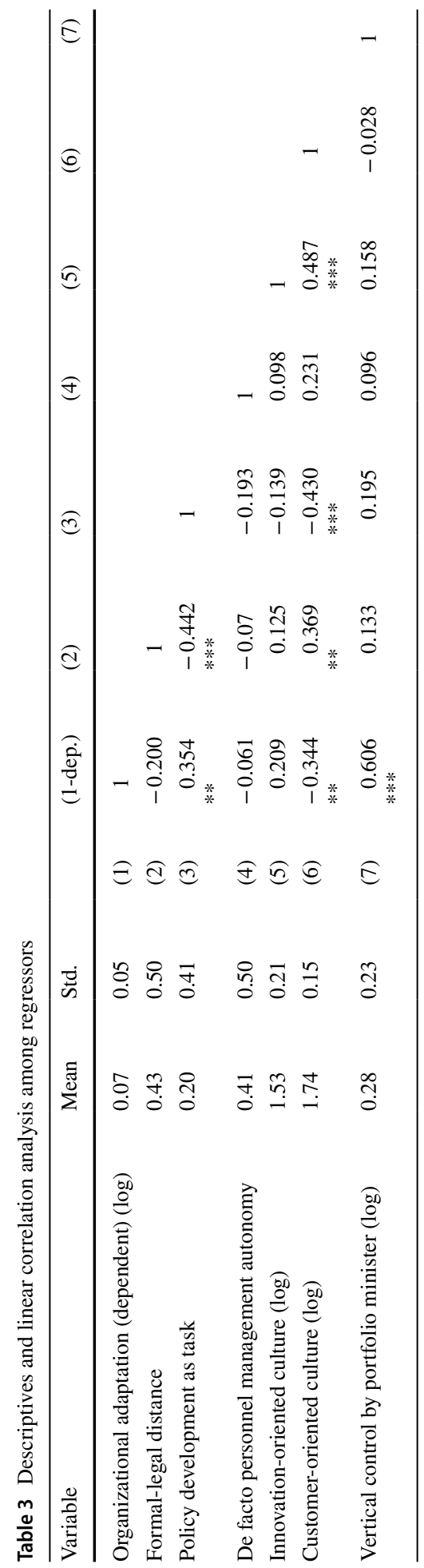


Table 4 Ordinary least squares (OLS)

\begin{tabular}{|c|c|c|c|}
\hline \multirow[t]{2}{*}{ Variables } & $\begin{array}{l}\text { Structural variables } \\
\text { Model (1) }\end{array}$ & $\begin{array}{l}\text { Structural + cul- } \\
\text { tural variables } \\
\text { Model (2) }\end{array}$ & $\begin{array}{l}\text { Structural + cul- } \\
\text { tural + vertical } \\
\text { control } \\
\text { Model (3) }\end{array}$ \\
\hline & Coeff. & Coeff. & Coeff. \\
\hline Formal-legal distance & $\begin{array}{l}-0.00570 \\
(0.0175)\end{array}$ & $\begin{array}{l}-0.00309 \\
(0.0161)\end{array}$ & $\begin{array}{l}-0.0160 \\
(0.0133)\end{array}$ \\
\hline Policy development as task & $\begin{array}{l}0.0423^{*} \\
(0.0218)\end{array}$ & $\begin{array}{l}0.0293 \\
(0.0202)\end{array}$ & $\begin{array}{l}0.00,482 \\
(0.0168)\end{array}$ \\
\hline De facto personnel management autonomy & $\begin{array}{l}-0.000161 \\
(0.0161)\end{array}$ & $\begin{array}{l}-0.00568 \\
(0.0147)\end{array}$ & $\begin{array}{l}-0.00607 \\
(0.0119)\end{array}$ \\
\hline Innovation-oriented culture (log) & & $\begin{array}{l}0.120 * * * \\
(0.0384)\end{array}$ & $\begin{array}{l}0.0893 * * * \\
(0.0310)\end{array}$ \\
\hline Customer-oriented culture (log) & & $\begin{array}{l}-0.177 * * * \\
(0.0612)\end{array}$ & $\begin{array}{l}-0.146^{* * * *} \\
(0.0488)\end{array}$ \\
\hline Vertical control by portfolio minister (log) & & & $\begin{array}{l}0.124 * * * \\
(0.0255)\end{array}$ \\
\hline Constant & $\begin{array}{l}0.0656 * * * \\
(0.0156)\end{array}$ & $\begin{array}{l}0.186^{*} \\
(0.0937)\end{array}$ & $\begin{array}{l}0.162 * * \\
(0.0742)\end{array}$ \\
\hline Observations & 44 & 44 & 44 \\
\hline R-squared & 0.128 & 0.343 & 0.600 \\
\hline
\end{tabular}

$* * * p<0.01 ; * * p<0.05 ; * p<0.1$. Standard errors in parentheses

is organizational size (FTE). As FTE might influence the capacity of an organization to adapt to crosscutting objectives, a model was run with this variable. As the number of observations is limited $(n=44)$, this alternative model was run without the variable on de facto personnel management autonomy. The results remained stable because, in the models reported here, the same significant effects were found.

In order to understand the effect of a portfolio minister's "vertical control" better, we also ran an alternative model with a dummy. This model measures whether or not the portfolio minister responsible for a respondent's organization, was also the portfolio minister of the organization's flag ship project (i.e., their most important crosscutting objective). This was the case for 19 out of the 44 organizations. The results stay the same with or without inclusion of this variable. Likewise, five of the 44 organizations were headed by the top civil servant, who simultaneously led the reported crosscutting objective as the administrative "champion." In order to check whether the presence of these five organizations in our sample distorted the results, we ran the same model excluding these five organizations. Again, results did not change. Therefore, the vertical control of the portfolio minister regarding crosscutting objectives has a positive effect on the level of organizational adaptation, irrespective of whether this portfolio minister or the top civil servant of the organization has a special role in coordinating the crosscutting objectives toward other organizations.

A final check we performed involved a model with the same variables as model 3 as well as an additional variable used to measure the extent to which the respondents felt that the crosscutting objective had close substantive links with the many ongoing activities performed by the organization they worked for. The logic behind this extra variable is that organizational adaptation to crosscutting objectives would be much easier to accomplish 
for organizations whose activities already had substantive links with the crosscutting objectives in question. This item was measured on a 5-point scale (strongly agree-somewhat agree—neither agree nor disagree—-somewhat disagree—strongly disagree). In this model, which is not shown here, the variable "substantive link with ongoing activities" has a positive significant effect on organizational adaptation $(\beta$ : 0.0477 ; significant at the 0.01 level; standard error: 0.0148). The variables that have a significant effect in model 3 retain their significant effect, except for the variable "innovation-oriented culture."

\section{Results}

Table 4 contains the results of the analyses. The table displays different models, each of which includes additional independent variables, allowing us to see how the effect of different clusters of variables (structural, cultural, vertical control) changes when additional variables are brought into the analyses.

When examining model 1 in Table 4, which describes a model in which we only considered structural factors, we noticed that "policy development as task" on its own has a positive significant effect on organizational adaptation. Organizations with policy development as a primary task are more likely to adapt to crosscutting objectives, compared to organizations with policy implementation as a task (like service delivery, regulation). As these organizations are close to the center, and close to their political principals, these organizations are engaged in more extended ways in the coordination of crosscutting objectives. In general, this feeling is widely shared; one interviewee illustrates this in the interview:

I can image adaptation is more extensive for organizations with policy development as a core task, as these organizations are expected to focus more on coordination, and to look for overarching elements, while agencies are much more focused on, "Okay, but what is in it for my client?" (Respondent, department \# 9)

Another respondent from an organization with policy implementation tasks explained, "We are an agency.... Whether we would like to join a collaboration depends on if we see an added value" (Respondent \# 25-agency). The interviews show that organizations with policy development as a core-task-which are often "departments"-mostly coordinate collaborative forums, vision documents, and so forth, so integrating such crosscutting activities in their work might be much easier than integrating them with substantive actions in case of organizations focusing on service delivery, regulation, or other forms of policy implementation. Organizations with a focus on policy implementation do not have such coordination tasks, and rather see when and where "a new program can have benefit for their clients" (Respondent \# 1, 4, 10, agency). These results show that having a policy development as a primary task is still important, in terms of program coordination. However, a respondent of one of the agencies says that it does not matter whether you are developing or implementing policy: "if there is a clear added value, people will start to adapt to the objectives" (Respondent \#21, agency).

The formal legal distance of the organization and its level of de facto personnel management autonomy have no separate individual effect on the level of organizational adaptation.

Although the organizational task is important, when we add cultural factors to the model, the effect of primary task disappears. In model 2 in Table 4, the two variables related to organizational culture were added, and they proved to be clearly significant. This suggests that one of the added significant cultural variables captures this effect. 
The $R^{2}$ value is almost triple that of model 1 , demonstrating that the inclusion of an organization's cultural values increases the explanatory value of the analysis to a large extent. Remarkably, organizations reported to be strongly characterized by an innovation-oriented culture are also more likely to exhibit a high level of organizational adaptation to crosscutting objectives. Respondents largely recognize this relevance of having an innovation-oriented organizational culture, with one respondent emphasizing: "leadership, a clear vision, and indeed innovation-orientedness are important for organizations to contribute to the cross-cutting objective" (Respondent \#8, public law agency, also Respondent \#3, department). Model 2 also indicates that organizations with a high self-reported score for customer-oriented culture are less likely to adapt to crosscutting objectives. One respondent explained this phenomenon in the following way: "This cross-cutting program required a lot of energy from our organization, with no return for our clients" (Respondent \#2, departmental agency). Also the abovementioned quotes of Respondents \# 9 and \# 25 testify that organizations, which are focused on clients, are very skeptical of what such crosscutting objectives might bring of value to their own clients. So, organizations with an innovation-oriented culture are more likely to contribute to crosscutting objectives, compared to organizations with a customer-oriented culture. Interviews support that a customer-oriented culture brings about a focus on ongoing business and the end-user. Crosscutting objectives and contributing to them entails for these organizations risks, as they are competing with statutory tasks and time for their clients, and organizations therefore see them as obstacles. However, this is not true for organizations focused on innovation: they embrace experimentation and creative risk taking. Moreover, one of the respondents states that in case of his/her own organization a focus on the client when combined with a focus on innovation did actually increase the level to which the organization wants to be involved, as certain objectives can have real consequences for its clients: "we advocated for a new decree, based on client-oriented objectives, less on structure and more on real-world results" (Respondent \# 5, agency).

In model 3, all variables are included-the structural and cultural variables, as well as the variable referring to the portfolio minister's vertical control (see Table 4). The effect of task is still absent; however, the effects of both organizational culture variables remain. Moreover, the portfolio minister's level of vertical control appears to be positive and strongly significant in terms of the level of organizational adaptation. One of the interviewees explains this effect of vertical control by the portfolio minister very clearly:

The minister forces us to collaborate on the administrative level. Contribution is not just a promise on paper: the minster wants to see real collaboration! He also evaluates the contribution of the top-level civil servants in their annual evaluation meeting. (Respondent \#4, public law agency)

Another respondent elaborated on this: "It is a clear engagement of our minister, so not at all a marginal issue for our organization" (Respondent \#22, departmental agency). The inclusion of this variable ("vertical control by the portfolio minister") increases the explanatory power of the analysis considerably, with an $R^{2}$ value of 0.60 in this model. Respondents feel that having a portfolio minister which actually controls the organizations in terms of how she deals with the crosscutting objective urge them to commit to this objective, allocate organizational responsibilities and resources to this objective and to integrate their progress into their monitoring and reporting, as their portfolio minster is for them the most important principal. All the interviews seem to confirm this finding. 


\section{Conclusion}

In this era of governance, coordination, policy integration, and cross-agency collaboration are heralded as ways to tackle cross cutting issues (Peters 2018; Candel and Biesbroek 2016). On the one hand, because many reforms have left the government apparatuses specialized, and yet fragmented. On the other hand, because wicked and complex policy issues need involvement of a broad range of organizations. So, coordination is bound to be a complex, time-consuming, and costly affair. The number of studies that look at the program design of these crosscutting initiatives is quite high. Yet, the number of studies that delve into organizational factors to explain the coordination challenges and enables are rather scarce.

This study has a few limitations. First, this paper presents only a small sample of respondents, which does not allow to study potential interaction effects (see below). Second, it does not measure real contribution, output or outcomes, but "organizational adaptation." This is merely an indication of effort and intention, than contribution. However, the crosscutting program described in this paper offers a unique chance to systematically compare all types of organizations, both qualitatively and quantitatively and to study the adaptation of crosscutting policy objectives at the implementation level. By doing so, it offers an insightful look into organizational factors influencing crosscutting program success, a level that has not received much attention in the literature on policy integration, joined-up governance, whole-of-government initiatives, or holistic government.

Table 5 shows the support for our hypotheses.

If we only take structural variables into account, we see that the task portfolio of an organization determines the behavior and role of the organization in the implementation of crosscutting objectives. A policy development task leads to a higher extent of organizational adaptation, compared to policy implementation. Organizations with such policy development task have more slack and resources to invest in such programs and often are appointed as policy coordinators (similar point in Bouckaert et al. 2010). In addition, for such organizations, crosscutting programs entail working on vision texts and strategies, and interacting with other actors. When an organization has a policy implementation task, crosscutting programs require changes in services and client-processes, which is a huge cost. This finding supports the idea that especially implementing organization feel that crosscutting objectives are claims for scarce resources (6 et al. 1999, pp. 27-28). This finding also reflects the Flemish practice, as crosscutting objectives are more of a priority for organizations with a policy development task.

We would have expected formal-legal distance (i.e., having an own legal identity) and de facto personnel management autonomy to have an effect on the level of organizational adaptation. Most studies in the literature draw attention to agencification and a high degree of autonomy as factors having a negative effect on the willingness to contribute to crosscutting coordination objectives. In our study, however, formal-legal distance and de facto personnel management autonomy had no effect on the level of organizational adaptation.

If we look to the second model, which includes both structural and cultural factors, first we observe that the effect of structure, more specifically having policy development as primary task, disappears. The effect of structure is certainly present, but seems to be related to culture. The structure of an organization explains for a certain part the culture. Culture seems to be a much stronger predictor of organizational adaptation, compared to structure. When long-term objectives are discussed, an organization focused on customers would rather focus on providing consistent and good services, instead of 


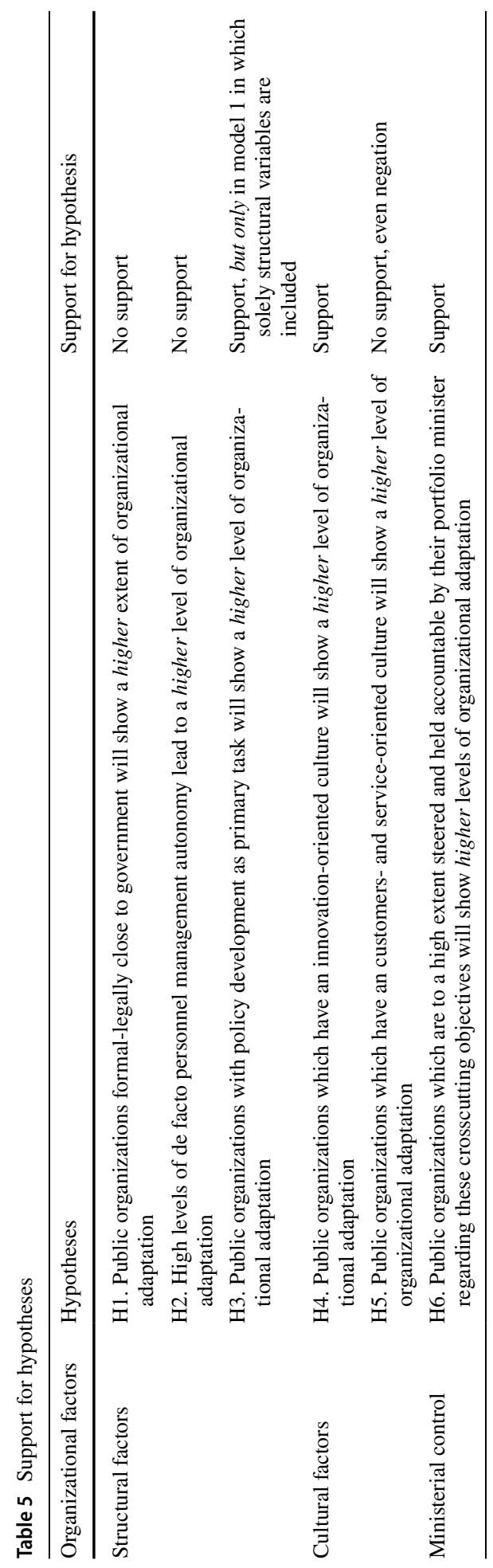


contributing to crosscutting objective, because these initiatives can mean shocks in the ongoing business, putting the quality and continuity of service delivery at risk. Innovative organizations, which do embrace risks, do invest relatively more in crosscutting objectives. Even if the immediate benefit is not clear, they can see future merits of the innovations a crosscutting objective might bring to their organization. This finding is consistent with the literature on innovation and open coordination.

The combination of an innovation culture and being held accountable by the portfolio minister shows to be a good indicator of the extent of organizational adaptation. This finding indicates that accountability and incentives, even in the case of crosscutting policy issues still follow traditional vertical lines. In the FiA program, we saw a lack of horizontal incentives and accountability mechanisms. There are a few soft coordination tools in place, but there is a clear lack of hard coordination tools, such as a mandate, decentralized control, accountability, incentive mechanisms, or dedicated resources (Carey and Crammond 2015, p. 1028). In this case, one has to fall back to vertical mechanisms, and the own organizational accountability structures. Hence, vertical control by the portfolio minister is the dominant accountability relation that can force organizations to contribute to crosscutting objectives. This causal effect remains strong even when the portfolio minister of the organization is not involved in the coordination of the involved FiA objective (see robustness check).

Some of the variables when combined might have a mutually reinforcing effect, or some variables might strengthen the link between a specific independent variable and the dependent variable (moderating effect). For instance, one could assume that the theoretically hypothesized positive effect of having low formal-legal distance on organizational adaptation would appear for those organizations which have policy development as primary task. Similarly one can theoretically assume that the positive effect of vertical control of the portfolio minister on organizational adaptation would even be stronger when combined with higher levels of innovation-oriented culture. Because of our small sample, we, however, cannot test for this interaction effect. We call upon the future research to study these potential interaction effects more explicitly.

The Flemish approach via a crosscutting program, initiated from the top-down from the center of government, with coordination instruments which should "fit" the structural and cultural diversity of all the organizations, seem to be an idea from the past. This analysis shows the diversity of organizations, and what kind of factors explains their contribution to crosscutting programs. This study clearly calls for tailor-made coordination arrangements - that embrace the cultural and structural diversity of organizations and balance vertical and horizontal accountability-in order to achieve policy integration and collaborative activities. Governments need to think about how to mix coordination instruments in order to stimulate policy integration on the implementation level (see e.g., Carey and Harris 2016; Meuleman 2008; O'Flynn et al. 2011; Voets et al. 2015).

Open Access This article is licensed under a Creative Commons Attribution 4.0 International License, which permits use, sharing, adaptation, distribution and reproduction in any medium or format, as long as you give appropriate credit to the original author(s) and the source, provide a link to the Creative Commons licence, and indicate if changes were made. The images or other third party material in this article are included in the article's Creative Commons licence, unless indicated otherwise in a credit line to the material. If material is not included in the article's Creative Commons licence and your intended use is not permitted by statutory regulation or exceeds the permitted use, you will need to obtain permission directly from the copyright holder. To view a copy of this licence, visit http://creativecommons.org/licenses/by/4.0/. 


\section{Appendix 1: Themes of Flanders in Action}

1. The open entrepreneur; an objective aimed at empowering entrepreneurs to be innovative in terms of products and processes, resulting in increased export of products and knowledge, and international growth.

2. Lifelong Learning: an objective aimed at enhancing the chances of elderly people, immigrants, people with disabilities, and the lowly educated, in education and on the labor market.

3. Innovation Centre Flanders; an objective aimed at enhancing the cross-fertilization between the scientists, entrepreneurs, and the government, so knowledge is translated into social, economic, and ecological results.

4. Green and dynamic urban region; new space in Flanders for houses and businesses is very limited. This objective is aimed at safeguarding the space that remains, but also to renew the urban areas which face various problems including deprivation, low quality of life, and accessibility.

5. Europe's smart hub; optimization of the existing transport modalities and researching new mobility infrastructure options which are future proof, with the aim to become an important and sustainable transport region.

6. Warm society; an objective aimed at battling the consequences of the aging population, and the increasing number of people in need of care in the society.

7. Decisive governance: an objective aimed at formulating clear organizational core tasks and enhancing accountability, resulting in an effective, efficient, and sustainable government.

As the program existed of over 300 actions, different parties favored different priorities. For instance, the social economic council ${ }^{2}$ of unions and employers associations put forward five priorities, which clearly relate to most of the themes in "Flanders in Action" (especially the abovementioned themes 1 to 6; with theme 7 "decisive government" being a precondition' to achieve the other goals'):

(1) Innovation, to improve the competitiveness of the economy. Flanders is lagging behind in terms of knowledge valorization.

(2) International business, the number of exporting companies in Flanders has showed a downward trend since 2009.

(3) Energy policy, Flanders still has relatively high energy consumption and is in a weak position because it is dependent on import for energy supply.

(4) Work, the current and future shortage on the labor market is likely to become a structural problem.

(5) Poverty, Flanders is doing well, compared to many other European countries. The absolute figures, however, continue to cause concern, with 1 in 8 Flemish people facing a risk of poverty.

\section{Appendix 2}

See Table 6.

2 Translate literally from: https://www.vlaanderen.be/publicaties/pact-2020-prioriteiten-in-de-uitvoering. 


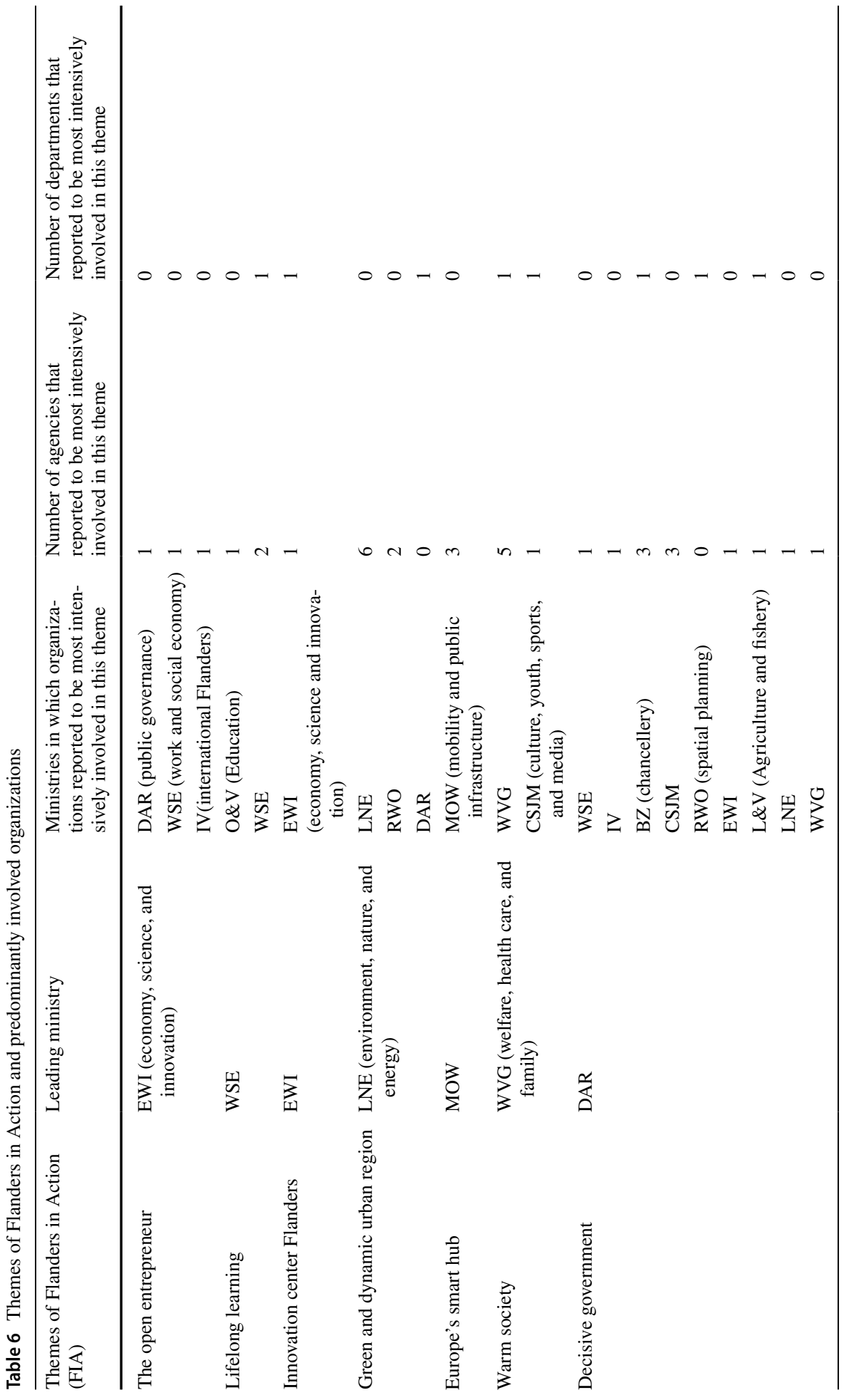




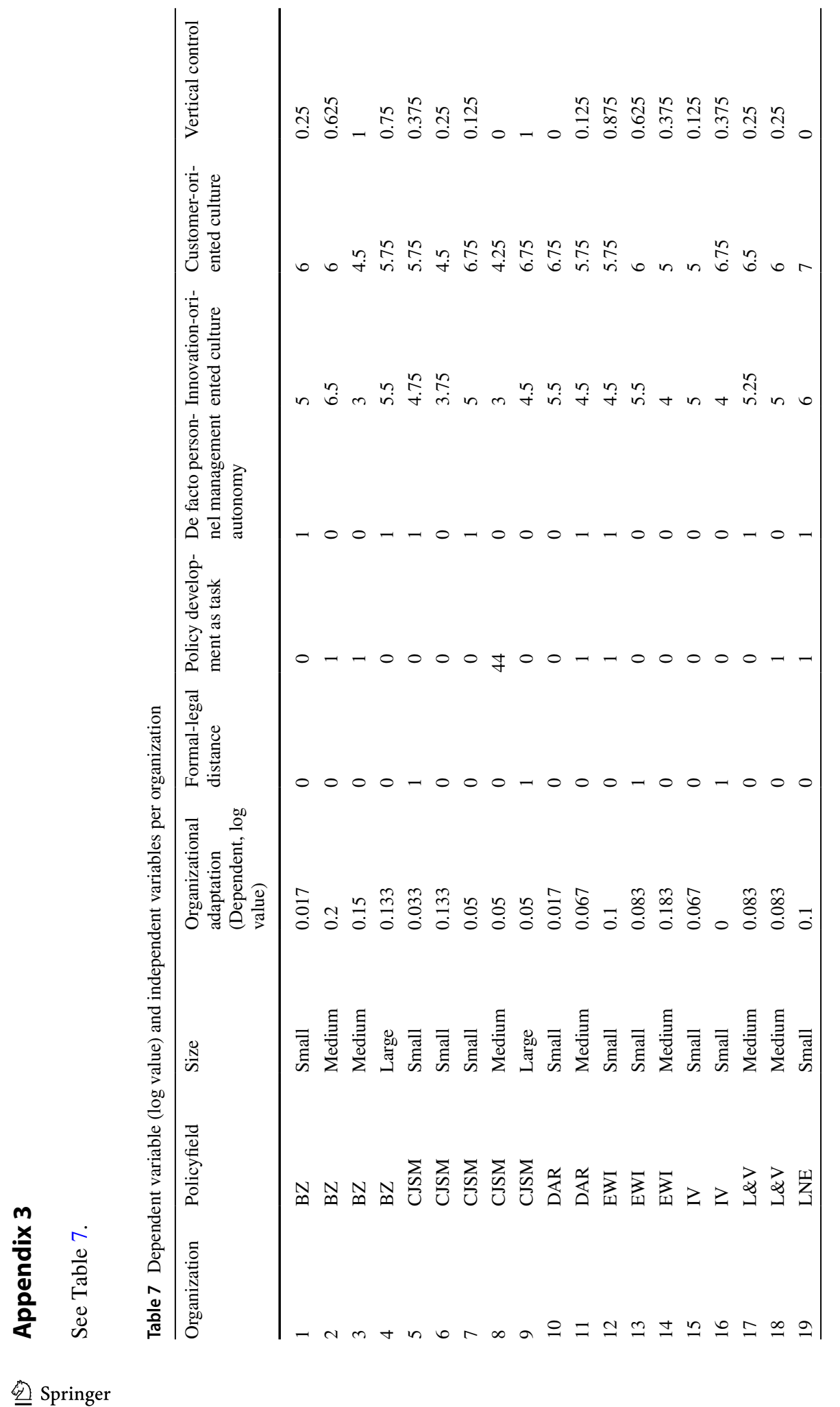




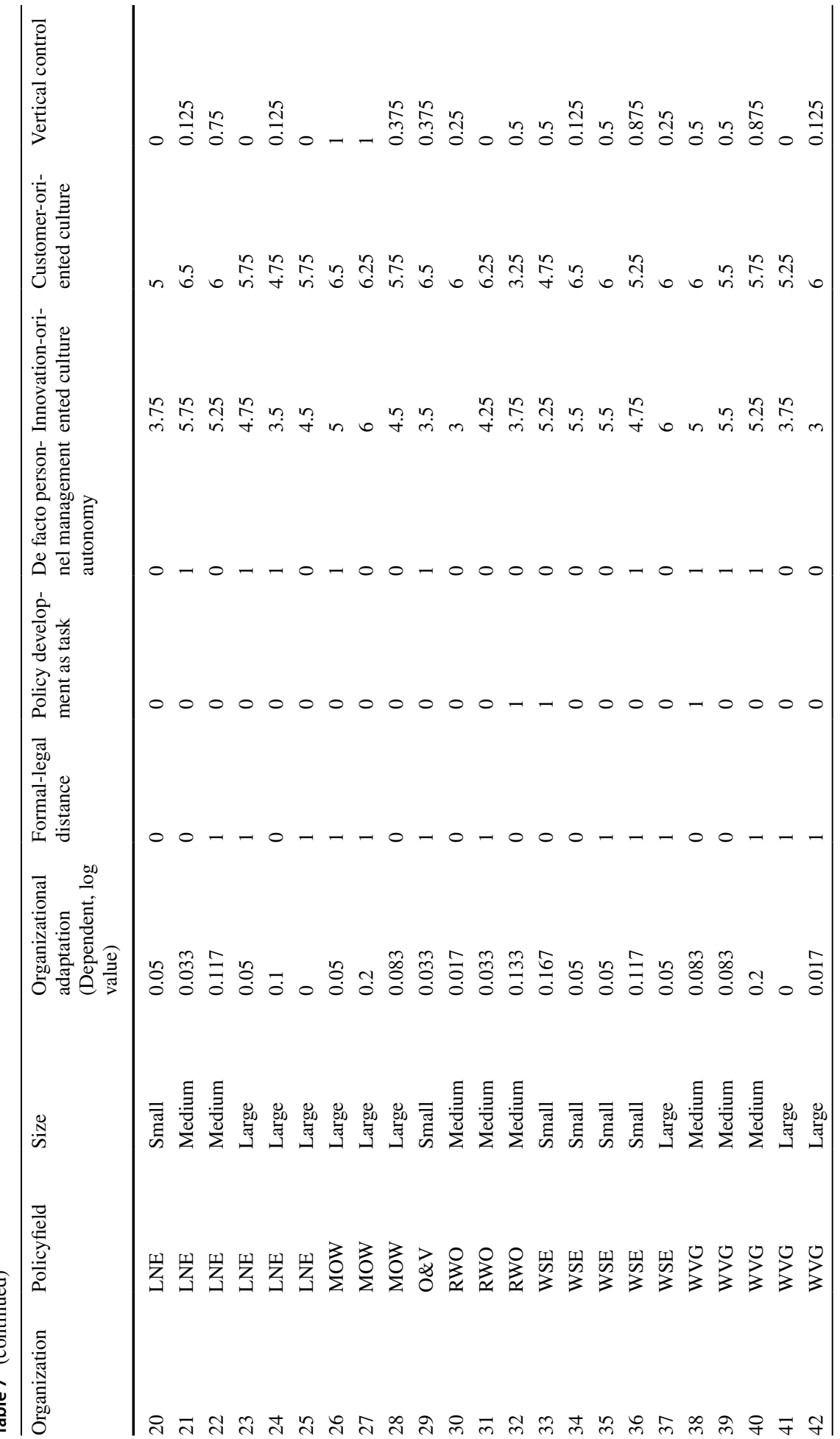




\begin{tabular}{|c|c|}
\hline 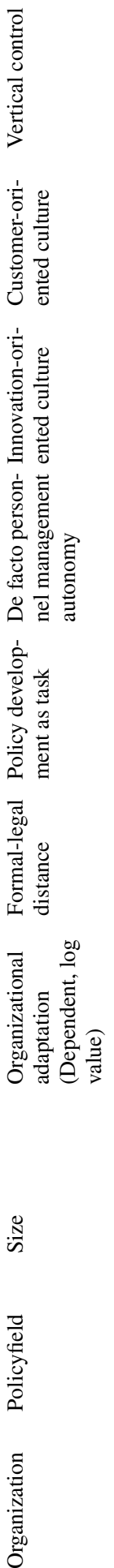 & 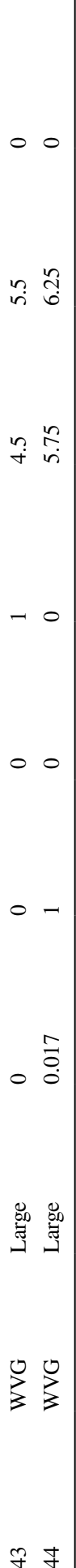 \\
\hline
\end{tabular}




\section{References}

6, Perri, Leat, D., Seltzer, K., \& Stoker, G. (1999). Governing in the round. Strategies for Holistic Government. London: Demos.

6, Perri, Leat, D., Setzler, K., \& Stoker, G. (2002). Towards Holistic Governance: The New Reform Agenda. Houndmills: Palgrave.

Agranoff, R. (2006). Inside collaborative networks: Ten lessons for public managers. Public Administration Review, 66(Special Issue), 56-65. https://doi.org/10.1111/j.1540-6210.2006.00666.x.

Alexander, E. R. (1995). How organizations act together, interorganizational coordination in theory and practice. Luxembourg: Gordon and Breach Publishers.

Bertelli, A. M. (2016). Who are the policy workers, and what are they doing? Citizen's heuristics and democratic accountability in complex governance. Public Performance \& Management Review, 40(2), 208-234

Bogdanor, V. (2005). Joined-up government., British Academy Occasional Paper 5 Oxford: Oxford University Press.

Bouckaert, G., Peters, G. B., \& Verhoest, K. (2010). The coordination of public sector organizations: Shifting patterns of public management. Hampshire: Palgrave Macmillan.

Bovens, M. (2007). Analysing and assessing accountability: A conceptual framework. European Law Journal, 13(4), 447-468. https://doi.org/10.1111/j.1468-0386.2007.00378.x.

Brans, M., \& Hondeghem, A. (2005). Competency frameworks in the Belgian governments: Causes, construction and contents. Public Administration, 83(4), 823-837. https://doi.org/10.111 1/j.0033-3298.2005.00478.x.

Candel, Jeroen J. L. (2017). Holy grail or inflated expectations? The success and failure of integrated policy strategies. Policy Studies, 38(6), 519-552. https://doi.org/10.1080/01442872.2017.1337090.

Candel, Jeroen J. L., \& Biesbroek, G. R. (2016). Toward a processual understanding of policy integration. Policy Sciences, 49(3), 211-231. https://doi.org/10.1007/s11077-016-9248-y.

Carayannopoulos, G. (2017). Whole of government: The solution to managing crises? Australian Journal of Public Administration, 76(2), 251-265. https://doi.org/10.1111/1467-8500.12227.

Carey, G., \& Crammond, B. (2015). What works in joined-up government? An evidence synthesis. International Journal of Public Administration, 38(13-14), 1020-1029. https://doi.org/10.1080/01900 692.2014.982292.

Carey, G., Crammond, B., \& Riley, T. (2015). Top-down approaches to joined-up government: Examining the unintended consequences of weak implementation. International Journal of Public Administration, 38(3), 167-178. https://doi.org/10.1080/01900692.2014.903276.

Carey, G., \& Harris, P. (2016). Developing management practices to support joined-up governance. Australian Journal of Public Administration, 75(1), 112-118.

Cejudo, G. M., \& Michel, C. L. (2017). Addressing fragmented government action: Coordination, coherence, and integration. Policy Sciences, 50(4), 745-767. https://doi.org/10.1007/s11077-017-9281-5.

Chisholm, D. (1992). Coordination without hierarchy: Informal structures in multiorganizational systems. Oxford: University of California Press Ltd.

Christensen, J. G. (2001). Bureaucratic autonomy as a political asset. In G. B. Peters \& J. Pierre (Eds.), Politicians, bureaucrats and administrative reform. London: Routledge.

Christensen, D. A., Christensen, T., Lægreid, P., \& Midtbø, T. (2012). Cross-border coordination activities in central government administration-combining organizational conditions and individual features. Public Organization Review, 12(4), 367-382. https://doi.org/10.1007/s11115-012-0178-7.

Christensen, T., Danielsen, O. A., Laegreid, P., \& Rykkja, L. H. (2016). Comparing coordination structures for crisis management in six countries. Public Administration, 94(2), 316-332. https://doi. org/10.1111/padm.12186.

Christensen, T., Fimreite, L. A., \& Lægreid, P. (2007a). Reform of the employment and welfare administrations the challenges of co-coordinating diverse public organizations. International Review of Administrative Sciences, 73(3), 389-408. https://doi.org/10.1177/0020852307081149.

Christensen, T., \& Lægreid, P. (2007). The whole-of-government approach to public sector reform. Public Administration Review, 67(6), 1059-1066.

Christensen, T., Lægreid, P., Roness, P. G., \& Røvik, K. A. (2007b). Organization theory and the public sector: Instrument, culture and myth. London/New York: Routledge. https://doi.org/10.4324/97802 03929216.

De Vries, H., Bekkers, V., \& Tummers, L. (2016). Innovation in the public sector: A systematic review and future research agenda. Public Administration, 94(1), 146-166. 
Emerson, K., Nabatchi, T., \& Balogh, S. (2012). An integrative framework for collaborative governance. Journal of Public Administration Research and Theory, 22(1), 1-29. https://doi.org/10.1093/jopar t/mur011.

Hall, A. (1987). The information matrix test for the linear model. The Review of Economic Studies, 54(2), 257-263.

Head, B. W., \& Alford, J. (2015). Wicked problems. Administration \& Society, 47(6), 711-739. https:// doi.org/10.1177/0095399713481601.

Jakobsen, M., \& Jensen, R. (2015). Common method bias in public management studies. International Public Management Journal, 18(1), 3-30.

Jordan, A., \& Schout, A. (2006). Coordination of the European Union: Exploring the capacities of networked governance. Oxford: Oxford University Press.

Jun, K.-N., \& Weare, C. (2010). Institutional motivations in the adoption of innovations: The case of e-government. Journal of Public Administration Research and Theory, 21(3), 495-519.

Karré, P. M., Alford, J., Van Der Steen, M., \& Van Twist, M. (2012). Whole of government in theory and practice: An exploratory account of how australian and dutch governments deal with wicked problems in an integrated way. In H. J. M. Fenger \& V. J. J. M. Bekkers (Eds.), Beyond fragmentation and interconnectivity (pp. 97-113). Amsterdam: IOS Press. https://doi.org/10.3233/978-1-60750 -998-1-97.

Karré, P. M., van der Steen, M., \& van Twist, M. (2013). Joined-up government in The Netherlands: Experiences with program ministries. International Journal of Public Administration, 36(1), 63-73. https://doi.org/10.1080/01900692.2012.713295.

Klijn, E.-H., \& Koppenjan, J. F. M. (2000). Public management and policy networks. Public Management: An International Journal of Research and Theory, 2(2), 135-158.

Klijn, E.-H., \& Koppenjan, J. (2016). Governance networks in the public sector. New York: Routledge.

Kollock, M. A., Hinde, R. A., Groebel, J., \& Ostrom, E. (1992). Governing the commons: The evolution of institutions for collective action contemporary sociology (Vol. 21). Cambridge: Cambridge University Press. https://doi.org/10.2307/2075554.

Lægreid, P., Randma-Liiv, T., Rykkja, L. H., \& Sarapuu, K. (2013). Cocops Work Package 5-Deliverable 5.3. Bergen.

Lægreid, P., Roness, P. G., \& Verhoest, K. (2011). Explaining the innovative culture and activities of state agencies. Organization Studies, 32(10), 1321-1347.

Laegreid, P., \& Rykkja, L. H. (2015). Organizing for 'Wicked Problems'-Analyzing coordination arrangements in two policy areas: Internal security and the welfare administration. International Journal of Public Sector Management, 28(6), 475-493. https://doi.org/10.1108/IJPSM-01-2015-0009.

Lægreid, P., Sarapuu, K., Rykkja, L. H., \& Randma-Liiv, T. (2014). Organizing for coordination in the public sector: Practices and lessons from 12 European countries. New York: Palgrave Macmillan.

Ling, T. (2002). Delivering joined-up government in the UK: Dimensions, issues and problems. Public Administration, 80(4), 615-642. https://doi.org/10.1111/1467-9299.00321.

Lombardo, G. A., \& Mulligan, R. F. (2003). Resource allocation: A Hayekian paradigm for maritime conglomerates. The Quarterly Journal of Austrian Economics, 6(1), 3-21. https://doi.org/10.1007/ s12113-003-1010-6.

Maggetti, M. (2012). Regulation in practice: The de Facto independence of regulatory agencies series editor: Regulation in practice: The de Facto independence of regulatory agencies. New York: ECPR Press.

Maggetti, M., \& Verhoest, K. (2014) Unexplored aspects of bureaucratic autonomy: a state of the field and ways forward. International Review of Administrative Sciences , 80(2), 239-256.

Meier, K. J., \& O'Toole, L. J., Jr. (2013). I think (I am doing well), therefore I am: Assessing the validity of administrators' self-assessments of performance. International Public Management Journal, $16(1), 1-27$.

Meuleman, L. (2008). Public management and the metagovernance of hierarchies, networks and markets: The feasibility of designing and managing governance style combinations. Dordrecht: Springer.

Meyer, J. W., \& Rowan, B. (1977). Institutionalized organizations: Formal structure as myth and ceremony. American Journal of Sociology, 83(2), 340-363. https://doi.org/10.1086/226550.

Moe, T. M. (1990). Political institutions: The neglected side of the story. Journal of Law Economics and Organization, 6, 213-253.

Molenveld, A., \& Verhoest, K. (2014). A cross-cutting program for coherence: Flanders in action. In P. Lægreid, K. Sarapuu, L. H. Rykkja, \& T. Randma-Liiv (Eds.), Organizing for coordination in the public sector. Practices and lessons from 12 European countries (pp. 117-128). London: Palgrave Macmillan. 
Molenveld, A., Verhoest, K., Voets, J., \& Steen, T. (2020). Images of coordination: How implementing organizations perceive coordination arrangements. Public Administration Review, 80(1), 9-22.

Nordbeck, R., \& Steurer, R. (2016). Multi-sectoral strategies as dead ends of policy integration: Lessons to be learned from sustainable development. Environment and Planning C, 34(4), 737-755. https://doi. org/10.1177/0263774X15614696.

O’Flynn, J. L., Buick, F., Blackman, D. A., \& Halligan, J. (2011). You win some, you lose some: Experiments with joined-up government. International Journal of Public Administration, 34(4), 244-254.

OECD. (2007). OECD reviews of human resource management in government: Belgium. Brussels-Capital Region, Federal Government, Flemish Government, French Community, Walloon Region. Paris: OECD.

Page, S. B. (2013). Theories of governance: Comparative perspectives on seattle' s light rail project. Policy Journal Studies, 41(4), 583-609. https://doi.org/10.1111/psj.12033.

Peters, G. B. (2015). Pursuing horizontal management: The politics of public sector coordination. Lawrence: University Press of Kansas.

Peters, G. B. (2018). The challenge of policy coordination. Policy Design and Practice, 1(1), 1-11. https:// doi.org/10.1080/25741292.2018.1437946org/10.1080/25741292.2018.1437946.

Podsakoff, P. M., MacKenzie, S. B., \& Podsakoff, N. P. (2012). Sources of method bias in social science research and recommendations on how to control it. Annual Review of Psychology, 63, 539-569.

Pollitt, C. (2003). Joined-up government: A survey. Political Studies Review, 1(1), 34-49. https://doi. org/10.1111/1478-9299.00004.

Rogers, D. L., \& Whetten, D. A. (1982). Interorganizational coordination: Theory, research, and implementation. IA: Iowa State University Press Ames.

Rommel, J., \& Christiaens, J. (2009). Steering from ministers and departments. Public Management Review, 11(1), 79-100. https://doi.org/10.1080/14719030802493569.

Ross, S., Frere, M., Healey, L., \& Humphreys, C. (2011). A whole of government strategy for family violence reform. Australian Journal of Public Administration, 70(2), 131-142.

Salamon, L. M. (2002). The tools of government: A guide to the new governance. The new governance and the tools of public action. Oxford: Oxford University Press.

Schillemans, T. (2013). Moving beyond the clash of interests: On stewardship theory and the relationships between central government departments and public agencies. Public Management Review, 15(4), 541-562. https://doi.org/10.1080/14719037.2012.691008.

Schillemans, T., \& Jacobs, S. (2014). Between a rock and a hard place. Organizations and the Media: Organizing in a Mediatized World, 30, 147.

Scott, T. A., \& Thomas, C. W. (2017). Unpacking the collaborative toolbox: Why and when do public managers choose collaborative governance strategies? Policy Studies Journal, 45(1), 191-214.

Serv. (2009). Advies Over de Tussentijdse Conclusies van de Commissie Effectieve En Efficiënte Overheid. Brussel: SERV.

Sorensen, E., \& Torfing, J. (2011). Enhancing collaborative innovation in the public sector. Administration \& Society, 43(8), 842-868. https://doi.org/10.1177/0095399711418768.

Swenden, W., Brans, M., \& De Winter, L. (2006). The politics of Belgium: Institutions and policy under Bipolar and centrifugal federalism. West European Politics, 29(5), 863-873. https://doi. org/10.1080/01402380600968729.

Tepeci, M. (2001). The effect of personal values, organizational culture, and person-organization fit on individual outcomes in the restaurant industry. The Pennsylvania State University. The Pennsylvania State University.

Termeer, C., Dewulf, A., \& Breeman, G. (2013). Governance of wicked climate adaptation problems. In J. Knieling \& W. L. Filho (Eds.), Climate change governance (pp. 27-41). Berlin: Springer. https://doi. org/10.1007/978-3-642-29831-8_3.

Thompson, J. (1967). Organizations in action. New York: McGraw-Hill.

Tosun, J., \& Lang, A. (2017). Policy integration: Mapping the different concepts. Policy Studies, 38(6), 553-570. https://doi.org/10.1080/01442872.2017.1339239.

Trein, P. (2017). Coevolution of policy sectors: A comparative analysis of healthcare and public health. Public Administration, 95(3), 744-758. https://doi.org/10.1111/padm.12323.

Trein, P., Meyer, I., \& Maggetti, M. (2019). Horizontal policy integration: A systematic review of the literature. Journal of Comparative Policy Analysis: Research and Practice, 21(4), 332-349.

van Bueren, E. M., Klijn, E.-H., \& Koppenjan, J. F. M. (2003). Dealing with wicked problems in networks: Analyzing an environmental debate from a network perspective. Journal of Public Administration Research and Theory, 13(2), 193-212. https://doi.org/10.1093/jopart/mug017. 
Van Thiel, S. (2012). Comparing agencies across countries. In K. Verhoest, S. van Thiel, G. Bouckaert, \& P. Lægreid (Eds.), Government agencies: Practices and lessons from 30 countries (Vol. 30, pp. 18-26). Basingstoke: Palgrave Macmillan.

Verhoest, K., Bouckaert, G., \& Peters, G. B. (2007). Janus-faced reorganisation: Specialisation and coordination in four OECD countries in the period 1980-2005. International Review of Administrative Sciences, 73(3), 325-348.

Verhoest, K., De Caluwé, C., Steen, T., \& Molenveld, A. (2013). Een Toekomstgericht OrganisatorischAdministratief Kader Voor Het Bestuurlijke Beleid van de Vlaamse Administratie. Analyse En Aanbevelingen. Antwerpen. http://www.vlabest.be/sites/default/files/20131911_VLABEST_rapport_finaa 1.pdf.

Verhoest, K., Demuzere, S., \& Rommel, J. (2012). Agencification in latin countries: Belgium and its regions. In K. Verhoest, S. Van Thiel, G. Bouckaert, \& P. Laegreid (Eds.), Government agencies: Practices and lessons from 30 countries (pp. 84-97). Basingstoke: Palgrave Macmillan.

Verhoest, K., Peters, G. B., Bouckaert, G., \& Verschuere, B. (2004). The study of organisational autonomy: A conceptual review. Public Administration and Development, 24(2), 101-118. https://doi. org/10.1002/pad.316.

Verhoest, K., \& Wynen, J. (2018). Why do autonomous public agencies use performance management techniques? Revisiting the role of basic organizational characteristics. International Public Management Journal, 21(4), 619-649. https://doi.org/10.1080/10967494.2016.1199448.

Voets, J., Verhoest, K., \& Molenveld, A. (2015). Coordinating for integrated youth care: The need for smart metagovernance. Public Management Review, 17(7), 981-1001.

Wynen, J., \& Verhoest, K. (2015). Do NPM-type reforms lead to a cultural revolution within public sector organizations? Public Management Review, 17(3), 356-379.

Wynen, J., Verhoest, K., Ongaro, E., \& Van Thiel, S. (2013). Innovation-oriented culture in the public sector: Do managerial autonomy andresult control lead to innovation?Public Management Review, 16(1), 45-66.

Yesilkagit, K., \& Van Thiel, S. (2008). Political influence and bureaucratic autonomy. Public Organization Review, 8(2), 137-153.

Yin, R. K. (2014). Case study research design and methods (5th ed.) Thousand Oaks, CA: Sage.

Publisher's Note Springer Nature remains neutral with regard to jurisdictional claims in published maps and institutional affiliations. 